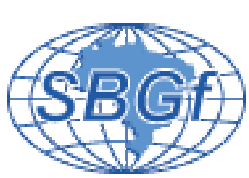

São Paulo 2004

\title{
Estudo geofísico do Complexo Alcalino de Pariquera Açu (SP) utilizando Métodos Eletromagnéticos.
}

\author{
Elaine Maria Lopes Loureiro, Prof. Dr. Marta Maria Mantovani, Mst. André Rugenski e Prof. Dr. Vagner Elis
}

\section{Resumo}

Este estudo enfocou dois métodos de prospecção geofísica: o método eletromagnético e eletrorresistivo para caracterização do complexo Alcalino de Pariquera Açu (SP), quanto à condutividade e à resistividade. Foram feitas algumas medidas de susceptibilidade magnética.

O Método Eletromagnético (EM34) foi muito eficiente para mapear o manto de alteração da alcalina, devido à presença de argila e produtos de intemperismo como goethita (derivada do piroxênio), gerando um forte contraste físico, visto que o manto de alteração apresenta alta condutividade, relativamente à alcalina. Concluí-se também que a cobertura sedimentar central é proveniente do intemperismo da alcalina, com pouca contribuição alóctone. A susceptibilidade da rocha encaixante é praticamente nula enquanto a susceptibilidade da alcalina é muito maior, apresentando um valor máximo de 1,98 no S.I. medido na rocha aflorante, composta possivelmente por theralitos. Isto ocorre devido à presença de magnetita e Ti-magnetita existente na rocha (Morbidelli et al., 2000).

O método de eletrorresistividade revelou um possível topo rochoso, de alta resistividade, muito fraturado, a profundidade aproximada de $40 \mathrm{~m}$ entre 220 e $680 \mathrm{~m}$ do caminhamento, apresentando resistividades que variam entre 600 a 2000. No mapa de cargabilidade nota-se também que há altos de IP na distância 430 e $850 \mathrm{~m}$. Estes pontos mostram que são regiões onde acontece a polarização, por conter maior quantidade de materiais condutivos, são facilmente polarizáveis.

\section{Introdução}

A região do Vale do Ribeira, situada no sul do Estado de São Paulo, tem sido objeto de estudos de importância científica e econômica. A última, graças à quantidade de minérios de importância, que são associados às rochas alcalinas. Como exemplo, podemos citar terras raras, carbonatitos, fosfatos e magnetita. Quanto à sua importância científica, as alcalinas são indicativas de afinamento litosférico passivo e ativo.

Este complexo alcalino já gerou diversos trabalhos geológicos, geoquímicos e geofísicos. Trabalhos geofísicos anteriores que utilizaram dados gravimétricos e aerogamaespectrométricos concluíram que o complexo apresenta heterogeneidades e uma possível fenitização externa à alcalina (Rugenski, 2001).

\section{Características da área - Localização e Geologia}

O termo rocha alcalina é definido para rochas ígneas que possuem alcális-feldspato ou feldspatóides como nefelina, sanidina, etc. (Sprensen,1974). A alcalina de Pariquera Açu é uma intrusão aflorante com área de $6 \mathrm{Km}^{2}$, sendo parcialmente coberta por sedimentos da Formação Pariquera Açu e material aluvionar. Sua forma é ovalada e com eixo maior na direção $45^{\circ} \mathrm{NW}$ (Algarte, 1972). A geologia local é mostrada na Figura I, onde se observa que a intrusão é cortada por uma falha, $80^{\circ} \mathrm{NE}$ (Silva \& Algarte, 1981). Usando o método de datação
$\mathrm{K} /$ Ar foram determinadas idades de $92 \pm 3 \mathrm{Ma}$ (em rochas essexíticas; Morbidelli et al., 2000).

A rocha encaixante teve origem no ciclo Brasiliano/Pan-Africano (0,9 - 0,5 Ga) (Almeida et al., 2000) e pertence à Seqüência Turvo-Cajati, grupo Setuva, (Silva \& Algarte, 1981; Campanha \& Sadowski, 1999) mais precisamente à subseqüência Cajati (Silva \& Batolla, 1981), sendo o grupo Setuva de idade Proterozóica Superior (Campanha \& Sadowski, 1999).

A subseqüência Cajati, apresenta como características litológicas: mica-xisto $\left(2,54-2,97 \mathrm{~g} / \mathrm{cm}^{3}\right)$ e mica-quartzo-xisto $\left(2,70-2,96 \mathrm{~g} / \mathrm{cm}^{3}\right)$, sendo que próximo da intrusão alcalina, é representada mais especificamente por quartzo-muscovita-biotita-xisto (2,65-3,19 $\left.\mathrm{g} / \mathrm{cm}^{3}\right)$, mica-xisto $\left(2,72 \mathrm{~g} / \mathrm{cm}^{3}\right)$, filito $\left(2,68-2,80 \mathrm{~g} / \mathrm{cm}^{3}\right)$ e metassiltito. Rochas gnaíssicas-migmatíticas, do Paleozóico Inferior, afloram a menos de $5 \mathrm{~km}$ da alcalina de Pariquera Açu, sendo sobreposta pelo grupo Setuva. O embasamento para a alcalina é, portanto configurado pelos metassedimentos do grupo Setuva e pelas rochas gnaíssicas-migmatíticas.

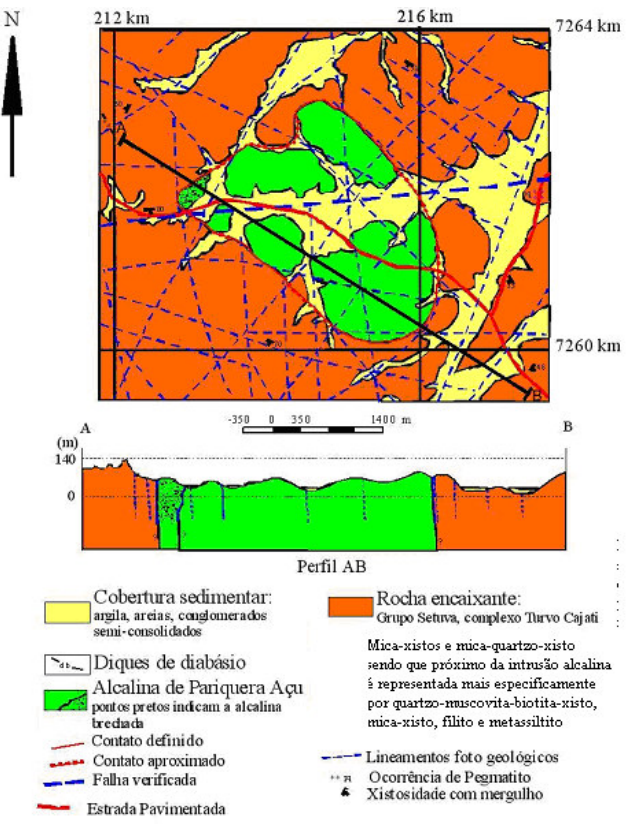

Figura I - Mapa geológico local da alcalina de Pariquera Açu (Ferreira et al., 1987).

\section{Métodos utilizados e ensaios realizados}

O software usado foi o SURFER da GOLDEN SOFTWARE para interpolação e "plotagem". O intervalo de amostragem utilizado na confecção da malha foi de $150 \mathrm{~m}$ para o método de EM34 e de $5 \mathrm{~m}$ para a resistividade. Os métodos de interpolação usados foram - da "Mínima Curvatura" para o EM34 e "Natural Neighboor" para o Método de eletrorresistividade. Estes parâmetros foram escolhidos por representarem melhor o conjunto de dados determinados com vários testes.

$A$ área estudada abrange $22 \mathrm{Km}^{2}$, referentes às latitudes de 212000 a 217500 e longitudes 7259500 a 
7263500. Os instrumentos utilizados foram o EM34-3 (GEONICS) e o SYSCAL, pertencentes ao IAG/USP.

\section{IV.A. EM34 e Susceptibilidade Magnética:}

O EM34 consiste em duas bobinas, uma transmissora $T x$ e outra receptora $R x$, conectadas por um cabo de tamanho pré-determinado. O funcionamento do equipamento consiste em aplicar uma corrente alternada na bobina transmissora $T x$ que produz um campo magnético primário $\mathrm{Hp}$. Este campo magnético varia em função do tempo, induzindo pequenas

$$
\sigma_{a}=\frac{4}{\omega \mu_{0} s^{2}}\left(\frac{H_{s}}{H_{p}}\right)
$$

correntes na terra. Conseqüentemente, estas correntes produzem um campo magnético secundário $H s$ que é captado pela bobina receptora $R x$. $\mathrm{Na}$ saída do equipamento lê-se diretamente a condutividade. A condutividade aparente do meio é determinada por: $\mathrm{H}_{\mathrm{s}}$ é o campo magnético secundário da bobina receptora $\mathrm{H}_{\mathrm{p}}$ é o campo magnético primário da bobina transmissora

$\omega=2 \pi f$, a freqüência angular

f é a freqüência $(\mathrm{Hz})$

$\mu_{0}$ é permeabilidade magnética no espaço livre

$\sigma_{a}$ é a condutividade de subsuperfície

( $\mathrm{mho} / \mathrm{m}=\mathrm{mS} / \mathrm{m}=\mathrm{ohm}^{-1} / \mathrm{m}$, segundo Weast et al., 1987)

$\mathrm{s}$ é o espaçamento entre as bobinas $(\mathrm{m})$

A profundidade de investigação é determinada através do cálculo do "skin depht" que é uma profundidade no semi-espaço em que as ondas eletromagnéticas são atenuadas de $1 / \mathrm{e}$ em suas amplitudes, dependendo do meio $\left(\sigma_{a}\right)$ e da freqüência da onda aplicada (f). O "skin depth" é calculado através da seguinte fórmula:

onde:

$$
\delta=\sqrt{\frac{2}{\omega \mu \sigma}}=503\left(\frac{1}{\mathrm{f} \sigma}\right)^{1 / 2}
$$

$\delta$ é o "skin depht"

$\omega=2 \pi f$, é a freqüência angular

$\mu$ é permeabilidade magnética do meio

$\sigma$ é a condutividade do meio $(\mathrm{mho} / \mathrm{m}=\mathrm{mS} / \mathrm{m})$

f é a freqüência $(\mathrm{Hz})$

As bobinas são usadas em duas configurações: horizontais, com dipolos dos campos magnéticos verticais (primário e secundário); ou verticais, com dipolos horizontais. $O$ alcance da profundidade de investigação para o cabo de $20 \mathrm{~m}$ é de $15 \mathrm{~m}$ e $30 \mathrm{~m}$ para bobinas verticais e horizontais respectivamente. A freqüência para 0 cabo de $20 \mathrm{~m}$, usado no estudo, é $1,6 \mathrm{MHz}$.

As medidas foram feitas com transmissor a distância de $50 \mathrm{~m}$ e o receptor a $70 \mathrm{~m}$ do veículo Toyota para que não houvesse interferência do carro das medições e também sendo evitadas aproximações com cercas ou fios elétricos que geram ruídos na aquisição. Houve uma preocupação adicional em manter as bobinas sempre coplanares.

A susceptibilidade magnética é determinada pela fórmula (Nussenzveiz, 2003):

$$
\mathrm{M}=\chi_{\mathrm{m}} \mathrm{H}
$$

Se tivermos um meio magnético linear, homogêneo e isotrópico, a magnetização $M$ será proporcional ao campo B (ou, equivalente, $\mathrm{H}$ ) no interior do meio, onde $\chi_{\mathrm{m}}$ é denominada susceptibilidade magnética do meio.

Os materiais magnéticos lineares são de dois tipos, diamagnéticos $\left(\mu<\mu_{0}, \chi_{m}<0\right)$ e paramagnéticos, $\left(\mu>\mu_{0}\right.$, $\chi_{m}>0$ ). Em ambos os casos, de efeitos muito pequenos, sendo a polarização de dielétricos muito mais forte (comparativamente), do que a magnetização destes materiais. Isso implica $\mu \approx \mu_{0}$ e $B \approx \mu_{0} H$. Efeitos fortes são encontrados apenas para materiais ferromagnéticos, mas estes são não-lineares.

As medidas de susceptibilidade foram obtidas localmente com um susceptibilímetro que mede a susceptibilidade relativa em relação ao ar.

\section{IV.B Eletrorresistividade:}

O método da eletrorresistividade foi aplicado em Pariquera Açu, utilizando a técnica de caminhamento dipolo-dipolo, com espaçamento entre os eletrodos $\mathrm{A}$ e $B$ e $M$ e $N$ de $20 \mathrm{~m}$. Este método foi utilizado em uma área menor subseqüente ao estudo do EM34. O perfil foi feito ao longo das estradas entre os pontos $A$ (coordenadas UTMX 214786 e UTMY 7261599) e B (coordenadas UTMX 215405 e UTMY 7261127). A Figura II mostra o local do levantamento.

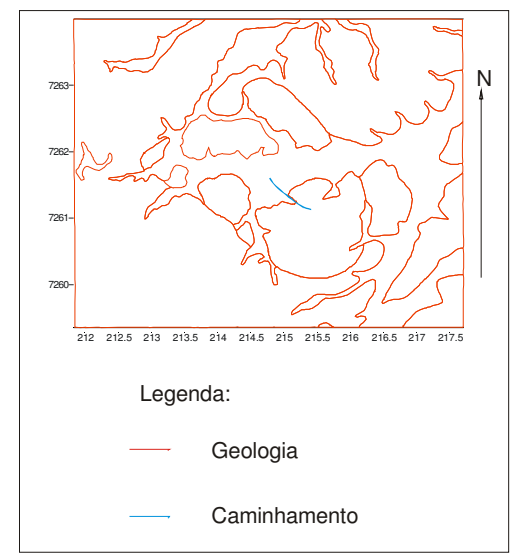

Figura II - Localização da linha do caminhamento elétrico (linha em azul), no mapa esquemático da geologia.

O método da eletrorresistividade consiste em utilizar eletrodos que são cravados no solo e através de uma fonte (no nosso caso foram utilizadas duas baterias de carro) que injetam corrente nos eletrodos A e B mede-se a diferença de potencial do alvo a ser estudado. O equipamento usado foi o SYSCAL do IAG/USP. Foram medidos estes potenciais em cinco níveis de profundidade (teóricos): 20, 30, 40, 50 e $60 \mathrm{~m}$. A resistividade é determinada por (Braga et al., 1998):

$$
\rho_{a}=K \cdot \frac{\Delta V}{I}
$$

Onde

$\rho_{\mathrm{a}}$ é a resistividade aparente (ohm.m);

$\mathrm{K}$ é um fator geométrico

$\Delta \mathrm{V}$ é a diferença de potencial $(\mathrm{mV})$;

I é a corrente aplicada (mA).

$n$ é constante e depende do número de níveis de investigação, neste caso, $K=1,2,3$, 4 e 5.

$$
K=2 \pi G x
$$

$x$ é a distância do espaçamento entre os eletrodos $A B$ e $M N$, neste estudo $x=20$ m e $G$ é: 


$$
G=\frac{n(n+1)(n+2)}{2}
$$

Logo:

$$
K=\pi x n(n+1)(n+2)
$$

Concluindo:

$$
\rho_{a}=x n(n+1)(n+2) \cdot \frac{\Delta V}{I}
$$

Foi medido também outro parâmetro físico: a cargabilidade aparente. A cargabilidade aparente trata da Polarização Induzida (IP) que é medida no domínio do tempo. Ao se aplicar uma corrente elétrica no solo, cria-se uma diferença de potencial primária $\left(\Delta \mathrm{V}_{\mathrm{p}}\right)$ que não se estabelece e nem se anula instantaneamente quando a corrente é emitida ou cortada em pulsos sucessivos. Esta polaridade varia com o tempo na razão $\Delta \mathrm{V}_{\mathrm{IP}}=\mathrm{f}(\mathrm{t})$.

Esta curva liga a assíntota $\Delta V_{P}$ em regime estacionário com a assíntota zero após o corte da corrente. A amplitude de um valor $\Delta \mathrm{V}_{\mathrm{IP}}(\mathrm{t})$ está diretamente ligada a uma maior ou menor capacidade que os terrenos têm de se polarizarem, constituindo-se, portanto, na base do método. Esta capacidade de polarização constitui a susceptibilidade IP dos materiais da Terra.

\section{Discussão dos resultados}

\section{V.A. Método Eletromagnético}

O método EM34 foi integrado ao de susceptibilidade magnética. As medidas de susceptibilidade magnética e EM34 são mostradas nas Figuras IIIA e IIIB.

(A) Bobina Vertical

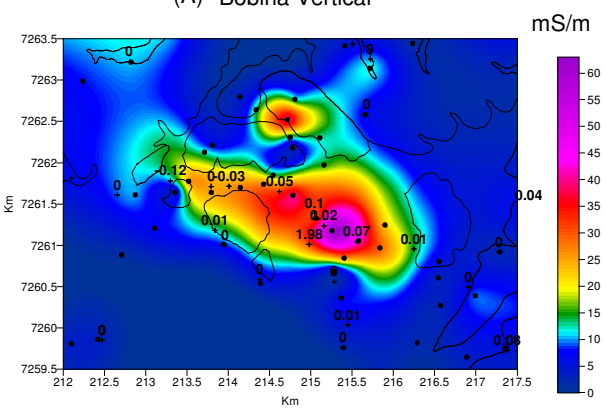

(B) Bobina Horizontal

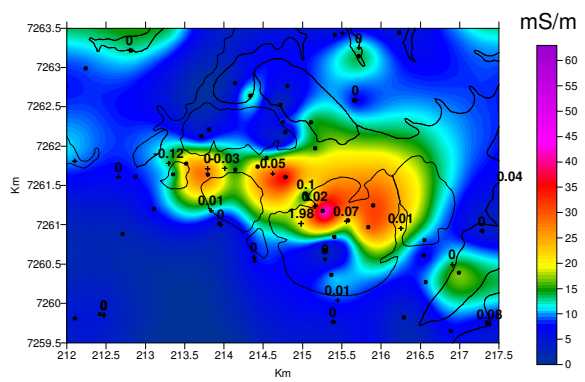

Figura III - Valores de condutividade $(\mathrm{mS} / \mathrm{m})$ usando o EM34: (A) bobina vertical com alcance de investigação de $15 \mathrm{~m}$ de profundidade; e (B) bobina horizontal, de $30 \mathrm{~m}$. As linhas em preto mostram a geologia da região; os números correspondem aos valores de susceptibi- lidade magnética medida no local. Os pontos são as estações de dados de EM34 e as cruzes representam as estações de medidas de susceptibilidade. Os valores de susceptibilidade apresentam variações em correspondência aos de condutividade.

Nos ensaios feitos com o EM34 nota-se uma alta condutividade na região central do Complexo Alcalino, sugerindo que a cobertura sedimentar do local seja um produto de intemperismo da rocha. Destaca-se que nas demais partes da alcalina, a condutividade é baixa.

Além disso, os dados de susceptibilidade são altos onde há afloramentos da alcalina $e$, na região central da cobertura sedimentar os valores de susceptibilidade são baixos.

\section{V.B. Método Eletrorresistivo}

Os perfis obtidos no caminhamento mostrando horizontes de resistividade e cargabilidade se mostraram compatíveis com o esperado (Figura IV). O manto de alteração se mostrou muito condutivo. A anomalia sugere a presença de um corpo heterogêneo à alcalina, de alta resistividade, muito fraturado. Pelo perfil apresentado, este corpo é possivelmente um topo rochoso e é encontrada a profundidade aproximada de $40 \mathrm{~m}$ entre 220 e $680 \mathrm{~m}$ do caminhamento. Estas possíveis rochas estão provavelmente alteradas apresentando resistividades que variam entre 600 a $2000 \Omega$. Há uma anomalia de em $880 \mathrm{~m}$ isolada que pode ser interpretada como sendo um possível matacão. No mapa de cargabilidade nota-se também que há altos de IP nas distâncias de 430 e 850 m. Estes pontos mostram que são regiões onde acontece a polarização, por conter maior quantidade de materiais condutivos, facilmente polarizáveis.

VI.

\section{Conclusões}

O Método Eletromagnético se mostrou eficaz para o mapeamento do manto de alteração, inclusive foi decisivo para entender o processo de lixiviação para interpretação dos mapas de raios gama. A alta condutividade, em ambas as configurações das bobinas, está localizada na parte central da alcalina, onde existe uma cobertura sedimentar. Isto se dá talvez por algum produto de alteração da alcalina: a presença de hematita, produto da alteração do piroxênio ou pela presença de argila.

Observando os dados de susceptibilidade, podese concluir que a rocha encaixante tem baixa susceptibilidade. $\mathrm{Na}$ alcalina, a susceptibilidade aumenta até mostrar um valor máximo de 1,98 no afloramento. Isto é provavelmente devido à presença de magnetita existente no theralito (Morbidelli et al., 2000).

Comparativamente aos dados de EM34 (bobina vertical), a susceptibilidade magnética possui gradientes que incidem com altos e baixos valores de condutividade (vide figura VII).

Já os dados de resistividade se mostraram muito mais quantitativos que os de EM, devido às várias profundidades de investigação permitidas pelo método. Graças a isso, foi possível ter uma idéia da profundidade do manto de alteração.

\section{Bibliografia}

Algarte, J.P., (1972). A influência dos arqueamentos cratônicos no condicionamento das alcalinas dos 
Estados de São Paulo e Paraná. Congresso Brasileiro, 26, Belém, 1972. SBG, v. 1, 65-69p.

Almeida, F.F. M., Brito Neves, B.B.de, Carneiro, C.D.R., (2000). The origin and evolution of the South American Platform. Earth-Science Reviews v. 50, 77-111p.

Braga, A.C.O.; Malagutti Filho, W.; Dourado, J.C.; Kiang, C.H. (1998). Correlation of electrical resistivity and induced polarization data with geotechnical survey standard penetration test (SPT) measurements". Journal of Environmental and Engineering Geophysics (JEEG) =The Environmental and Engineering Geophysical Society (EEGS), vol. 4, n² 2, 1999, p.35- 42.

Campanha G.A. and Sadowski, G.R., (1999). Tectonics of the southern portion of Ribeira belt (Apiai Domain). Precambrian Research, v. 98, 31-51p.

Morbidelli, L., Gomes, C.B., Brotzu, P., Acquarica, S.D., Garbarino, C. (2000). The Pariquera Açu K-alkaline complex and southern Brazil lithospheric mantle source characteristics. Journal of Asian Earth Sciences. V. 18, 129-150p.
Rugenski, A., (2001). Modelo gravimétrico do complexo alcalino de Pariquera-Açu (SP). Revista Brasileira de Geociências, 31 (3), 365-374p.

Silva, A.T.S. F., Algarte, J.P., (1981). Contribuição à geologia da Sequência Turvo-Cajati entre o Rio Pardo e Pariquera-Açu, Estado de São Paulo. 1. Litologia e petrografia, Simpósio Regional de Geologia, 3, Curitiba, 1981. Atas. São Paulo, SBG Vol.1, 109-120p.

Silva, A.T.S.F. \& Batolla Jr., F., (1981). Projeto Integração Vale do Ribeira. Relatório final. São Paulo: CPRM. Capítulo 4

Sфrensen, H., (1974). The alkaline rocks. Printed John Wiley \& Sons, 1-622p..
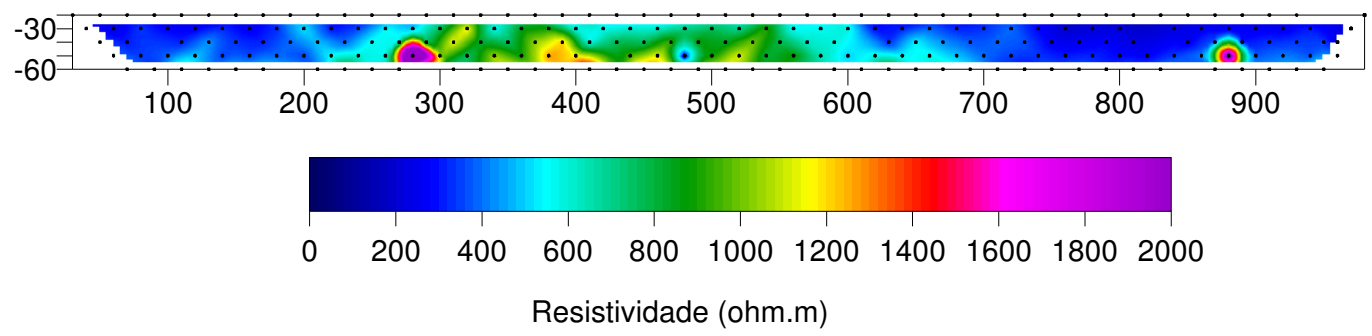

(B ) Cargabilidade (ohm.m)

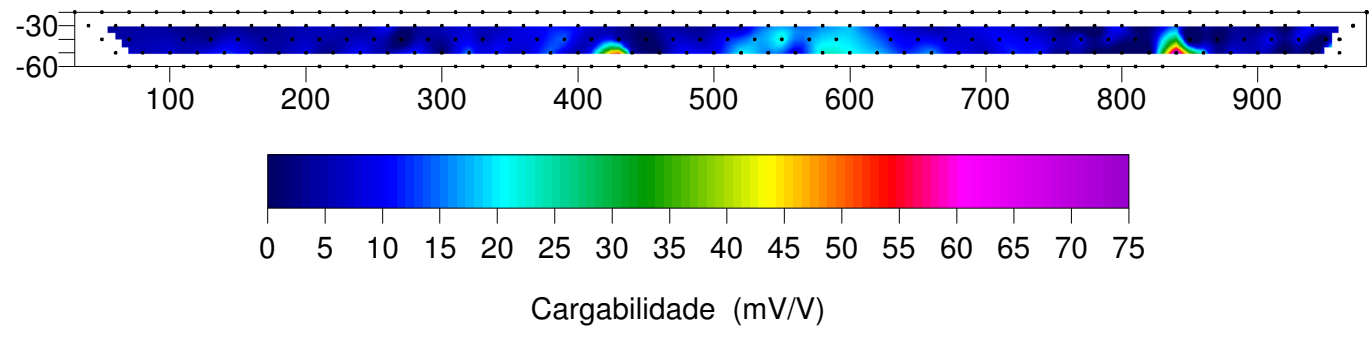

Figura IV - Perfis resultantes do caminhamento elétrico (C.E.) feito em Pariquera. (A) Perfil de resistividade aparente e (B) Perfil de cargabilidade aparente. Os pontos em preto correspondem à localização dos dados obtidos. 